\title{
Turning hand hygiene into a habit: the need is obvious
}

\author{
C. Ruef
}

Published online: 21 September 2010

(C) Urban \& Vogel 2010

The positive impact of hand disinfection on the incidence of nosocomial infections has been demonstrated numerous times since Semmelweis published his famous study in the 19th century. Nevertheless, this topic comes up regularly during infection control committee meetings in hospitals all over the world. Experts throw up their hands in despair about poor compliance rates with the well-known indications for hand hygiene. The topic is studied through many approaches. More recently, attention has shifted to behavioral aspects and options to modify behavior in order to improve compliance, not just by a few percentage points, but rather by a larger leap. In this issue of infection, Mathai et al. [1] provide a review on ways to educate healthcare workers on the topic of optimal hand hygiene practice. Some of the authors are responsible for the World Health Organization (WHO) program called the "First Global Patient Safety Challenge". The key point of this thorough review is that formal education programs are not sufficient by themselves to guarantee better adherence to hand hygiene protocols. The authors make clear that it is necessary to work on this from different angles, including working on facility infrastructure and supplies, as well as on aspects that may be particular to individual institutions.

The need to turn hand hygiene into a habit has probably never been as obvious as now with the growing problem of antibiotic resistance worldwide. Antibiotic resistance is not just a passing problem but is perpetuated by the fact that many patients turn into chronic carriers of antibioticresistant pathogens. This point is illustrated by another study published in this issue of infection. Mattner et al. [2]

C. Ruef $(\square)$

Division of Infectious Diseases and Hospital Epidemiology, University Hospital of Zurich, Zurich 8091, Switzerland

e-mail: christian.ruef@usz.ch demonstrate that more than half of patients found to be colonized with methicillin-resistant Staphylococcus aureus (MRSA) remain positive during later admissions. In fact, in their study, it is exceedingly rare that patients loose their MRSA carriage over time. Similar findings have been published by other authors. In a recent study, we showed that decolonization regarding MRSA was only successful in $47 \%$ of patients [3]. Decolonization is even more difficult or often not possible regarding other resistant pathogens, such as vancomycin-resistant enterococci (VRE) or multi-resistant gram-negative pathogens such as Acinetobacter baumannii. This means that healthcare facilities have to be prepared to deal with increasing numbers of patients colonized with multi-resistant pathogens. Given this fact, one would think that every educated healthcare worker voluntarily contributes to the prevention of transmission of these pathogens by adhering to the well-known and effective recommendations regarding the use of hand hygiene during clinical practice. Reality shows that we have a long way to go before we reach this ambitious butin the interest of our patients-justified goal.

\section{References}

1. Mathai E, Allegranzi B, Seto WH, Chraïti M-N, Sax H, Larson E, Pittet D. Educating healthcare workers to optimal hand hygiene practices: addressing the need. Infection. 2010. doi:10.1007/ s15010-010-0047-7.

2. Mattner F, Biertz F, Ziesing S, Gastmeier P, Chaberny IF. Longterm persistence of MRSA in re-admitted patients. Infection. 2010. doi:10.1007/s15010-010-0038-8.

3. Ruef C, Ruef SA, Senn G, Cathomas A, Imhof A. Decolonisation of patients with wounds colonised by MRSA. J Hosp Infect. 2009;72:88-90. 